NASA/TM-2012-217644

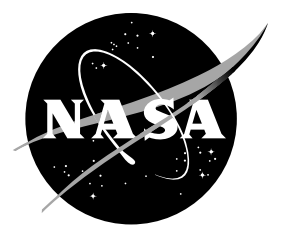

\title{
Analyses of Hubble Space Telescope Aluminized-Teflon Insulation Retrieved After 19 Years of Space Exposure
}

Kim K. de Groh and Deborah L. Waters

Glenn Research Center, Cleveland, Ohio

Jelila S. Mohammed

Goddard Space Flight Center, Greenbelt, Maryland

Bruce A. Perry

Ohio Aerospace Institute, Brook Park, Ohio

Bruce A. Banks

Alphaport, Inc., Cleveland, Ohio 


\section{NASA STI Program . . . in Profile}

Since its founding, NASA has been dedicated to the advancement of aeronautics and space science. The NASA Scientific and Technical Information (STI) program plays a key part in helping NASA maintain this important role.

The NASA STI Program operates under the auspices of the Agency Chief Information Officer. It collects, organizes, provides for archiving, and disseminates NASA's STI. The NASA STI program provides access to the NASA Aeronautics and Space Database and its public interface, the NASA Technical Reports Server, thus providing one of the largest collections of aeronautical and space science STI in the world. Results are published in both non-NASA channels and by NASA in the NASA STI Report Series, which includes the following report types:

- TECHNICAL PUBLICATION. Reports of completed research or a major significant phase of research that present the results of NASA programs and include extensive data or theoretical analysis. Includes compilations of significant scientific and technical data and information deemed to be of continuing reference value. NASA counterpart of peer-reviewed formal professional papers but has less stringent limitations on manuscript length and extent of graphic presentations.

- TECHNICAL MEMORANDUM. Scientific and technical findings that are preliminary or of specialized interest, e.g., quick release reports, working papers, and bibliographies that contain minimal annotation. Does not contain extensive analysis.

- CONTRACTOR REPORT. Scientific and technical findings by NASA-sponsored contractors and grantees.
- CONFERENCE PUBLICATION. Collected papers from scientific and technical conferences, symposia, seminars, or other meetings sponsored or cosponsored by NASA.

- SPECIAL PUBLICATION. Scientific, technical, or historical information from NASA programs, projects, and missions, often concerned with subjects having substantial public interest.

- TECHNICAL TRANSLATION. Englishlanguage translations of foreign scientific and technical material pertinent to NASA's mission.

Specialized services also include creating custom thesauri, building customized databases, organizing and publishing research results.

For more information about the NASA STI program, see the following:

- Access the NASA STI program home page at http://www.sti.nasa.gov

- E-mail your question to help@sti.nasa.gov

- Fax your question to the NASA STI Information Desk at 443-757-5803

- Phone the NASA STI Information Desk at 443-757-5802

- Write to: STI Information Desk NASA Center for AeroSpace Information 7115 Standard Drive Hanover, MD 21076-1320 
NASA/TM-2012-217644

(2)

Analyses of Hubble Space Telescope Aluminized-Teflon Insulation Retrieved After 19 Years of Space Exposure

Kim K. de Groh and Deborah L. Waters

Glenn Research Center, Cleveland, Ohio

Jelila S. Mohammed

Goddard Space Flight Center, Greenbelt, Maryland

Bruce A. Perry

Ohio Aerospace Institute, Brook Park, Ohio

Bruce A. Banks

Alphaport, Inc., Cleveland, Ohio

Prepared for the

10th International Space Conference on Protection of Materials and Structures From the Space Environment (ICPMSE-10J)

cosponsored by ITL, MDA, CSA, JAXA, Kobe University Graduate School of Engineering, and the Society for Promotion of Space Science

Bankoku-Shinryokan, Okinawa, Japan, June 12-17, 2011

National Aeronautics and

Space Administration

Glenn Research Center

Cleveland, Ohio 44135 


\section{Acknowledgments}

The authors would like to thank Ben Reed and the Hubble Space Telescope Project Office at the NASA Goddard Space Flight Center (GSFC) for their support of this project. We greatly appreciate the opportunity to analyze this unique material and provide the results to the space community. We would also like to thank the following people from GSFC for their contributors to testing and analysis: Bryan Abbamonte, Josh Abel, David Hughes, Kristin McKittrick, Aparna Boddapati, Debbie Thomas, and Mollie Powell.

Trade names and trademarks are used in this report for identification only. Their usage does not constitute an official endorsement, either expressed or implied, by the National Aeronautics and Space Administration.

Level of Review: This material has been technically reviewed by technical management.

Available from

NASA Center for Aerospace Information 7115 Standard Drive

Hanover, MD 21076-1320
National Technical Information Service 5301 Shawnee Road Alexandria, VA 22312

Available electronically at http://www.sti.nasa.gov 


\title{
Analyses of Hubble Space Telescope Aluminized-Teflon Insulation Retrieved After 19 Years of Space Exposure
}

\author{
Kim K. de Groh and Deborah L. Waters \\ National Aeronautics and Space Administration \\ Glenn Research Center \\ Cleveland, Ohio 44135 \\ Jelila S. Mohammed \\ National Aeronautics and Space Administration \\ Goddard Space Flight Center \\ Greenbelt, Maryland 20771 \\ Bruce A. Perry \\ Ohio Aerospace Institute \\ Brook Park, Ohio 44142 \\ Bruce A. Banks \\ Alphaport, Inc. \\ Cleveland, Ohio 44135
}

\begin{abstract}
Since its launch in April 1990, the Hubble Space Telescope (HST) has made many important observations from its vantage point in low Earth orbit (LEO). However, as seen during five servicing missions, the outer layer of multilayer insulation (MLI) has become successively more embrittled and has cracked in many areas. In May 2009, during the 5th servicing mission (called SM4), two MLI blankets were replaced with new insulation pieces and the space-exposed MLI blankets were retrieved for degradation analyses by teams at NASA Glenn Research Center (GRC) and NASA Goddard Space Flight Center (GSFC). The MLI blankets were from Equipment Bay 8, which received direct sunlight, and Equipment Bay 5, which received grazing sunlight. Each blanket contained a range of unique regions based on environmental exposure and/or physical appearance. The retrieved MLI blanket's aluminizedTeflon (DuPont) fluorinated ethylene propylene (Al-FEP) outer layers have been analyzed for changes in optical, physical, and mechanical properties, along with space induced chemical and morphological changes. When compared to pristine material, the analyses have shown how the Al-FEP was severely affected by the space environment. This paper reviews tensile properties, solar absorptance, thermal emittance, x-ray photoelectron spectroscopy (XPS) data and atomic oxygen erosion values of the retrieved HST blankets after 19 years of space exposure.
\end{abstract}

\section{Introduction}

The HST was launched on April 25, 1990 into LEO as the first mission of NASA's Great Observatories program. It is a telescope capable of performing observations in the near-ultraviolet, visible and near-infrared wavelengths. The HST was designed to be serviced on-orbit to upgrade scientific capabilities. Five servicing missions (SM) have taken place, with the last mission occurring in May 2009 after 19 years in space. During servicing mission 2 (SM2), in February 1997, severe cracking of the 5 mil Al-FEP outer layer of the multilayer insulation (MLI) blankets was observed on the light shield (LS), forward shell and equipment bays of the telescope (Refs. 1 and 2). Patches of 2 mil thick $(50.8 \mu \mathrm{m})$ Al-FEP were placed over the worst cracks in MLI on Equipment Bays 8 and 10 (2 patches were attached to each bay). 
In May 2009 during the 5th servicing mission (called SM4), two degraded MLI blankets that were originally installed on the telescope were replaced with new insulation pieces, called New Outer Blanket Layers (NOBLs), and the space exposed MLI blankets were brought back for analysis by teams at NASA Glenn Research Center and NASA Goddard Space Flight Center. No other spacecraft material has been retrieved and analyzed after having this length of space exposure. The two blankets retrieved during SM4 included Equipment Bay $8 \mathrm{MLI}$, which received direct sunlight, and Equipment Bay $5 \mathrm{MLI}$, which received grazing sunlight. Also retrieved were remnants of the two patches that were placed over cracked areas on Bay 8 during SM2. The retrieved MLI blankets' Al-FEP outer layers were found to be highly degraded and have been analyzed for changes in optical, physical, and mechanical properties, along with space induced chemical and morphological changes and heat induced changes. This paper reviews the tensile properties, solar absorptance, thermal emittance, XPS data and atomic oxygen erosion values of the retrieved HST blankets after 19 years of space exposure.

\section{Materials and Environmental Exposure}

\section{HST SM4 Bays 5 and 8 MLI}

The Bays 5 and 8 MLI blankets originally installed on HST (exposed to space for 19.1 years), and 2 mil Al-FEP patches installed on Bay 8 on February 18, 1997 during SM2 (exposed to space for 12.2 years) were retrieved by astronauts on May 18, 2009 during SM4. As can be seen in the illustration in Figure 1, Bay 8 is located $15^{\circ}$ from the $+\mathrm{V} 3$ solar facing axis, and therefore is almost directly facing the sun. Bay 5 faces towards the $+\mathrm{V} 2$ solar array drive arm direction, and at $75^{\circ}$ from the $+\mathrm{V} 3$ direction, receives grazing sunlight. The environmental effects that cause degradation of the MLI are primarily temperature cycling, solar radiation, particle radiation, and atomic oxygen.

\section{Environmental Exposure}

The sun exposure on each bay was determined by the science pointing profile of HST. The attitude profile between 1/1/00 and SM4 was analyzed to determine the "typical" attitude of HST. The results were then extrapolated to provide estimates of the sun exposure since launch. Equivalent hours of sun exposure (ESH) of the telescope from deployment to SM4 are estimated as 111,000 hr, based on time in orbit, average time exposed to the sun per orbit, and length of each orbit. Based on the attitude profile from 2000 and SM4, and extrapolating over mission life, Bay 5 was exposed to $\sim 24,300 \mathrm{ESH}$ and the unpatched and patched areas of the Bay 8 MLI were exposed to $\sim 89,300$ and $\sim 30,300 \mathrm{ESH}$, respectively.

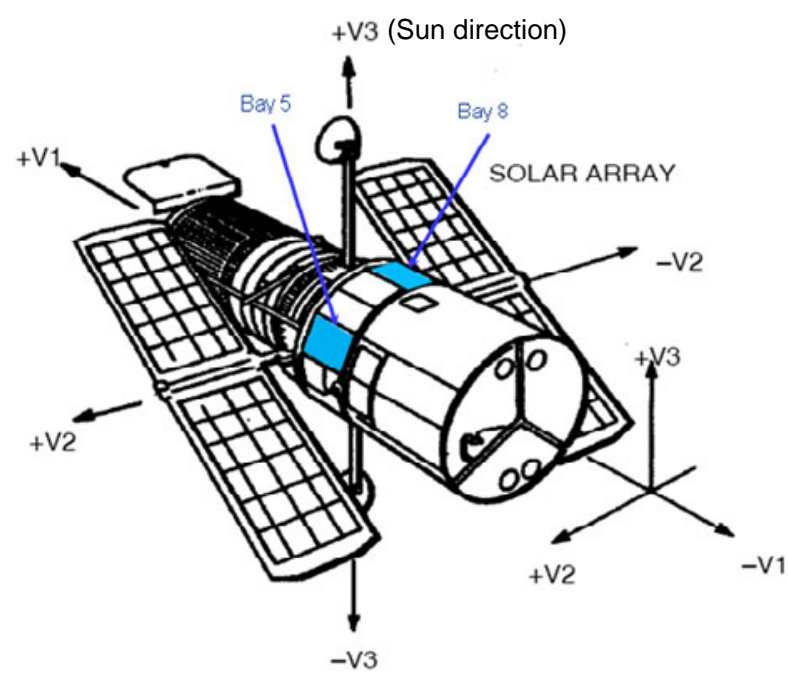

Figure 1.-Locations and orientations of Bays 5 and 8 on HST (+V3 is the solar facing axis). 
The HST underwent an estimated 110,000 thermal cycles overall, from deployment to SM4. The range of temperatures seen by Bays 5 and 8 vary greatly, because they are dependent on HST attitude and environmental heating variables. Thermal Desktop was used to model the Bays 5 and 8 MLI and simulate the general thermal cycling behavior. Bay 5 MLI temperatures were estimated to range from -175 to $0{ }^{\circ} \mathrm{C}$ and the Bay 8 temperatures were estimated to range from -175 to $40{ }^{\circ} \mathrm{C}$, for the attitude and orbit configurations modeled.

The x-ray fluence for solar facing surfaces was computed to be $641.1 \mathrm{~J} / \mathrm{m}^{2}$ between $1-8 \AA$ and 43.1 J/m $\mathrm{m}^{2}$ between 0.5-4 $\AA$. Data for x-ray fluence is based on x-ray flux data from the Geosynchronous Operational Environmental Satellites (GOES) for the time period of launch (1990) through SM2 (February 1997) (Ref. 3). For SM2 through SM4, the x-ray fluence was estimated assuming an average 11-year solar cycle (Ref. 3).

Electron and proton fluence from solar wind particles trapped in Earth's magnetic field have been calculated from deployment until December 9, 1999 using NASA's proton and electron models, AP-8 and AE-8, respectively (Ref. 3). The data for SM4 were extrapolated from these prior data, and indicated the Bays 5 and 8 MLI received an electrons fluence of $5.6 \times 10^{13}$ particles $/ \mathrm{cm}^{2}$ for electrons $>40 \mathrm{keV}$, and a proton fluence of $5.4 \times 10^{10}$ particles $/ \mathrm{cm}^{2}$ for protons $>40 \mathrm{keV}$.

The atomic oxygen fluence was computed for the duration of the HST mission over the period of time from deployment to SM4. This was accomplished by adding: 1) the prediction over the period of time from deployment to SM1 as predicted by SAIC's version 5.0 Environmental Work Bench, which uses MSIS-86 atmospheric model, to 2) a prediction based on orbital and atmospheric data from NASA Goddard for SM1 to SM4. The parameters used in the SM1 to SM4 fluence calculation included altitude, atmospheric density, and orbital velocity corrected for the Earth's atmosphere co-rotation. Based on these calculations the total ram fluence was $2.61 \times 10^{21}$ atoms $/ \mathrm{cm}^{2}$. If the surfaces of Bay 8 are $15^{\circ}$ from solar facing, then the fluence would be $\sim 25.8$ percent of the ram fluence or $\sim 6.73 \times 10^{20}$ atoms $/ \mathrm{cm}^{2}$. But, as the surfaces are solar facing but randomly tipped (always with Bay 8 somewhat towards the sun), then the fluence is decreased an additional factor of $2 / \pi$ resulting in the probable fluence of $\sim 4.28 \times 10^{20}$ atoms $/ \mathrm{cm}^{2}$. Because the Bay 5 faces towards the $+\mathrm{V} 2$ direction and is $75^{\circ}$ off the solar facing axis, the fluence was estimated as $\sim 28.0$ percent of the ram fluence, or $7.30 \times 10^{20}$ atoms $/ \mathrm{cm}^{2}$. As the surfaces are randomly tipped, the fluence would be decreased by $2 / \pi$ resulting in a probable fluence of $\sim 4.65 \times 10^{20}$ atoms $/ \mathrm{cm}^{2}$.

\section{Experimental Procedures}

A DDL Inc. Model 200Q Electromechanical Test System was used to determine the loaddisplacement data from which elongation to failure (percent elongation) and ultimate tensile strength (UTS) were determined. The tensile samples were sectioned to the specifications defined in American Society for Testing and Materials (ASTM) Standard D-638 for Type V tensile specimens (Ref. 4). Care was taken to avoid cracks and impact sites. The initial grip distance was set at $25.4 \mathrm{~mm}$ and the test speed was $12.7 \mathrm{~mm} / \mathrm{min}$.

Solar absorptance and thermal emittance measurements were taken at both GSFC and GRC. Both as-retrieved and heat-treated samples were measured at GRC. Initially, heat treatment was planned to be conducted at two temperatures: 120 and $200{ }^{\circ} \mathrm{C}$ (the highest temperature reached for very tightly curled insulation (Refs. 2 and 5)). But, finally, only the effect of moderate on-orbit heating $\left(120^{\circ} \mathrm{C}\right)$ was evaluated. Heating was conducted for $96 \mathrm{hr}$ as prior data indicates a minimum of $72 \mathrm{hr}$ is necessary to heating effects to be stabilized (Ref. 6).

Cary 5000 spectrophotometers equipped with Spectralon integrating spheres were used to measure total reflectance from 250 to $2500 \mathrm{~nm}$ at an $8^{\circ}$ angle of incidence at both GSFC and GRC. Absorptivity data were integrated with respect to the air mass zero solar spectrum to obtain solar absorptance. Samples at GRC were measured with an Al spacer backed by a single layer of sample of the quilted Al/Kapton/Al inner film (Region 8.15) replicating the on-orbit configuration. 
Emissivity measurements were obtained at GSFC using a Gier-Dünkle DB-100 InfraRed Reflectometer following the ASTM E408-71 standard test method. The normal emittance $\left(\varepsilon_{\mathrm{n}}\right)$ of the surface was measured from 5 to $40 \mu \mathrm{m}$ while at room temperature. Three measurements were taken for each sample, with the exception of Bay 8 Region 3, which was highly delaminated, hence only one measurement was taken. Emissivity measurements were obtained at GRC using a Surface Optics Corporation Model SOC 400T Reflectometer. The SOC 400T measures the directional reflectance of surfaces over a large spectral range, 2 to $25 \mu \mathrm{m}$, to obtain the directional thermal emittance over a large temperature range. Automatic integration of reflectivity data in the infrared with respect to blackbody curves is used to calculate total emittance for a selectable temperature range. Data were obtained at 293, 313 , and $393 \mathrm{~K}$. The samples were placed in the sample holder face-down with an aluminum spacer and were backed by a sample of the quilted Al/Kapton/Al MLI inner layer.

Samples for thickness measurements were mounted in epoxy, and then SiC paper and diamond slurry were used to polish the cross sections. Thickness measurements were taken at three locations along each sample's cross-section, using a scanning electron microscope (SEM).

Atomic oxygen erosion yield (Ey) of the HST samples ( $\mathrm{cm}^{3} /$ atom) was calculated in two separate ways, by mass loss and by thickness loss measurements. The mass of $12.7 \mathrm{~mm}$ diameter circular samples were measured using a Mettler M3 balance and compared to the mass of pristine material to determine mass loss. The mass loss was divided by the sample area $\left(1.366 \mathrm{~cm}^{2}\right)$, density and the atomic oxygen fluence to determine Ey. Erosion yield determined by thickness loss was computed by dividing the thickness loss in $\mathrm{cm}$ by the atomic oxygen fluence.

Samples were analyzed for elemental composition using a M-Probe X-Ray Photoelectron Spectrometer. Three locations on samples from various regions were run using a general survey scan, with a spot size of $800 \mu \mathrm{m}$, to determine atomic percent composition.

\section{Results and Discussion}

To retrieve the MLI blankets, astronaut John Grunsfeld unpeeled each blanket from its Velcro secured border, then folded the blankets and placed them into EVA storage bags. Although great care was taken in retrieval planning and execution, the retrieval process did cause cracking at fold seams, introducing handling cracks that were not present on-orbit prior to retrieval.

The Bays 5 and 8 MLI blankets are shown in the on-orbit photos taken during SM4 in Figures 2(a) and (b), respectively. As can be seen, the Bay 5 MLI has several large cracks extending from the two rectangular radiator areas. The Bay $8 \mathrm{MLI}$ also has several very large cracks, and one side of the largest crack on Bay 8 curled up into a cone-like roll, as seen in Figure 2(b). Also, the Bay 8 patches were seen to be highly degraded with the majority of the Al-FEP completely gone. Upon post-retrieval visual inspection, the Bay 8 MLI appeared significantly more degraded than the Bay 5 MLI, as the Bay 8 MLI was broken into many pieces after removing it from the EVA bag, unfolding it and laying it flat again. In fact, the Bay 8 Al-FEP outer layer needed to be reassembled post-flight like a puzzle.

\section{Exposure Regions}

The retrieved Bays 5 and 8 MLI blankets contained a range of unique regions which were identified based on environmental exposure and/or physical appearance and given assigned numbers. For example, the Bay 8 MLI that was not covered by patch material and was exposed to the space environment for the full 19.1 years had areas with three distinct appearances: shiny areas, hazy-white areas and areas where the Al was delaminated. These regions were defined as Regions 8.1, 8.2, and 8.3, respectively. Also, as mentioned, one of the Bay 8 outer layer Al-FEP cracked areas (not covered by patch material) curled up into a cone-like roll. In the curled region, the backside Al was exposed to the space environment, therefore this material heated to a higher temperature on-orbit than the nominal space-facing FEP because of the low emittance of the aluminized surface. This "curled" area was divided into two regions: a tightly curled region (8.7) and a loosely curled region (8.8), as those two regions may have heated differently on-orbit. 


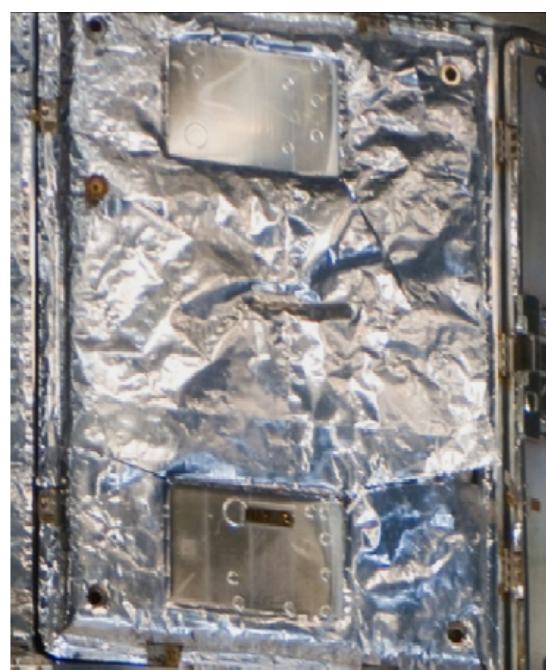

(a)

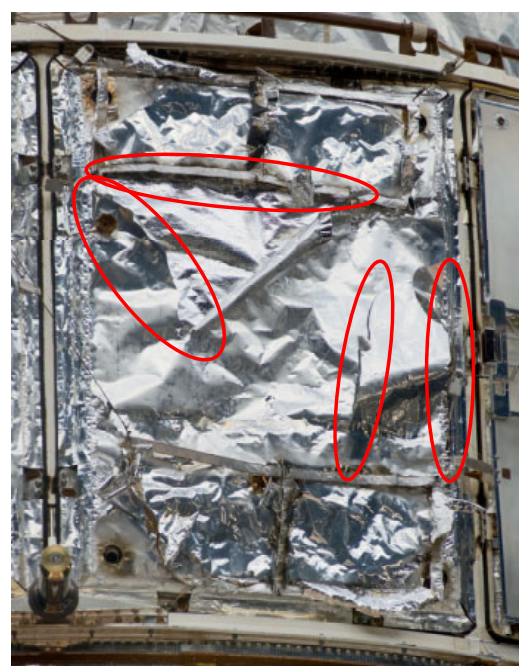

(b)

Figure 2.-On-orbit photos of Equipment Bays 5 and 8 just prior to retrieval during SM4: (a) Bay 5, and (b) Bay 8 (composite photo of two on-orbit images) with large cracks circled.

TABLE 1.-HST SM4 BAYS 5 AND 8 REGION DEFINITIONS

\begin{tabular}{|c|l|}
\hline $\begin{array}{c}\text { HST material } \\
\text { bay region }\end{array}$ & \multicolumn{1}{|c|}{ Description } \\
\hline Pristine (P) & Pristine 5 mil Al-FEP \\
\hline 5.1 & Nominal/Shiny \\
\hline 5.4 & Nominal/Al-delaminated \\
\hline 8.1 & Nominal/Shiny \\
8.2 & Nominal/White hazy \\
8.3 & Nominal/Al-delaminated \\
8.7 & Cone/Tight curl \\
8.8 & Cone/Loose curl \\
8.11 & Patched SM2-SM4 \\
8.13 & Patched SM2-SM3B \\
8.15 & Protected inner layer \\
& (Al/Kapton/Al) \\
\hline
\end{tabular}

Some areas of the patches installed during SM2 eventually degraded exposing the underlying MLI to the space environment once again as observed during SM3B and SM4. Therefore, the MLI under the patched areas are divided into two regions: region patched during SM2 and exposed by SM3B (SM2-SM3B, patched 5.1 years, called 8.13), and region patched during SM2 and still covered at SM4 (SM2-SM4, patched 12.2 years, called 8.11).

A total of 10 different regions were identified on Bay 5 (R1-R10), and 15 different regions were identified on Bay 8 (R1-R15) and four regions identified on the retrieved Patches (R16-19). The regions selected for testing are defined in Table 1. During sectioning of samples from the blankets, care was taken to avoid any cracks or imperfections in the samples which would affect the tests.

The delaminated regions of Bays 5 and 8 appear very different, and were likely caused by different factors. Bay 5 delaminated samples have a checkerboard-like pattern of delaminated areas on a surface that has predominately retained its Al backing. Bending these samples indicated that there is no tendency for more Al to flake off. In contrast, Bay 8 delaminated samples have small patches of Al sprinkled throughout a mostly delaminated surface and additional Al separates from the FEP on handling the samples. 


\section{Tensile Properties}

The average UTS and percent elongation at failure of the HST and pristine Al-FEP are shown in Figures 3(a) and (b), respectively. Because of the degree of embrittlement of the HST samples, many broke while being punched out or handled prior to testing. Others were tested but failed at pre-existing cracks, causing a premature break. Data from premature breaks were not included in the average. Five samples from Region 8.7 were tested, and all broke prematurely, thus no data are reported.

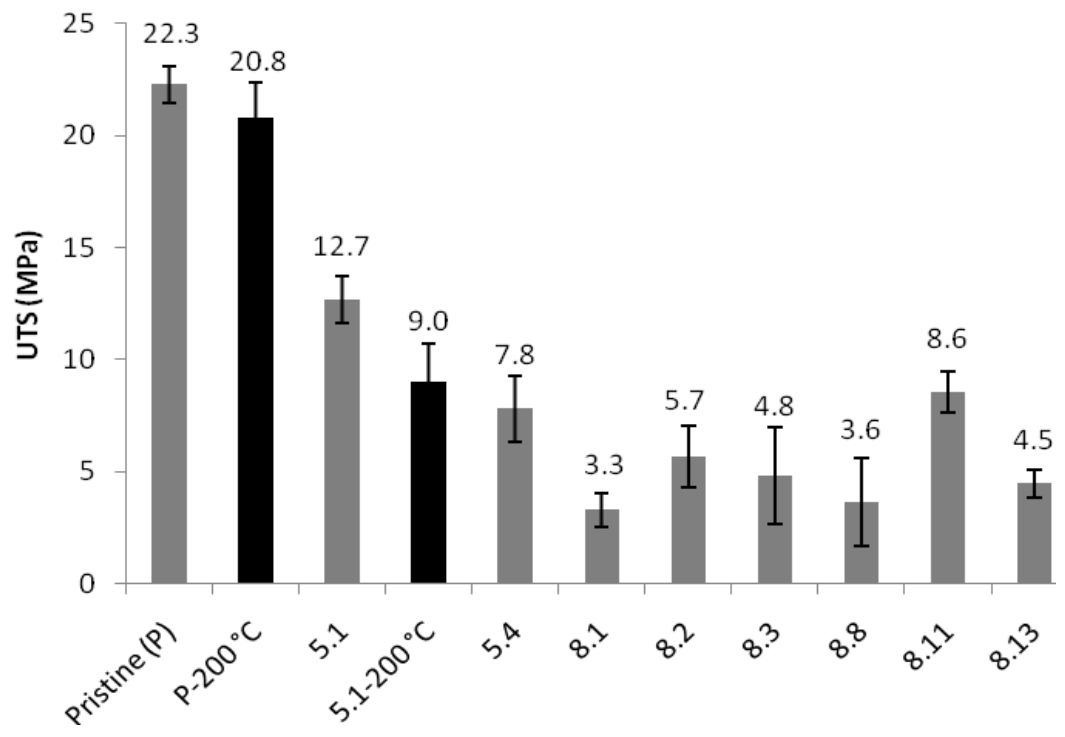

(a)

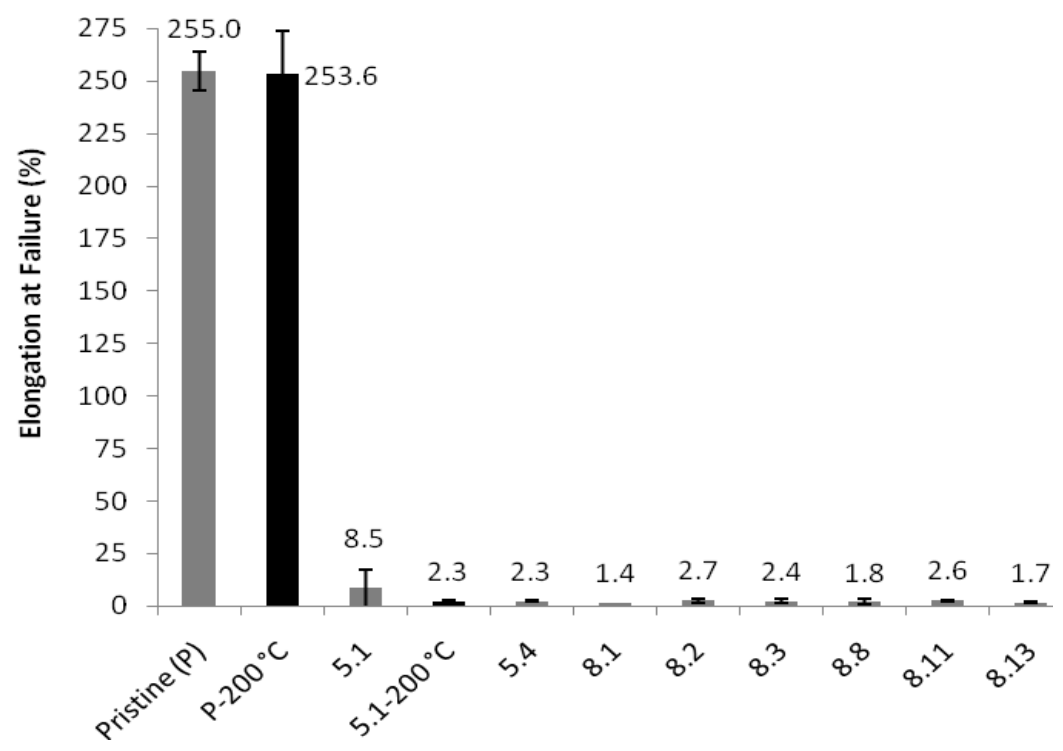

(b)

Figure 3.-Tensile properties of pristine and HST AI-FEP: (a) Average UTS and (b) Average elongation at failure. 
All HST material was extremely embrittled. Elongation at failure was reduced from 255 percent for pristine material to 8.5 percent for Bay 5 nominal/shiny material and to 1.4 percent for Bay 8 nominal/ shiny material. The Bay 8 Al-FEP, which had a significantly higher solar exposure and on-orbit thermal cycling temperature, was found to fracture very easily with handling, like thin brittle glass. All regions also experienced large decreases in UTS, from 22.3 MPa for pristine Al-FEP to 12.7 and $3.3 \mathrm{MPa}$ for Bays 5 and 8 nominal/shiny material, respectively. Although the standard deviation is large compared to some of the absolute values, both the UTS and the elongation at failure appears to correlate with the amount of solar exposure a sample received. For example, the solar facing Bay 8 material is more embrittled than the solar grazing Bay 5 material, and the elongation at failure of Bay 8 material is proportional to the amount of time that it was patched.

Heating pristine Al-FEP marginally decreased its strength, and had no effect on elongation. The Bay 8 MLI was too embrittled to conduct studies to assess the effect of heating, but heating Bay 5 Region 1 material at $120^{\circ} \mathrm{C}$ for $96 \mathrm{hr}$ further reduced both the elongation and strength of the samples. This supports the mechanism proposed for degradation in which solar radiation and solar heating play synergistic roles.

\section{Optical and Thermal Properties}

The as-retrieved and $120^{\circ} \mathrm{C}$-heated solar absorptance values obtained at GSFC and GRC are shown in Figure 4. It should be noted that the pristine Al-FEP absorptance obtained at GRC (0.15) was slightly higher than the value obtained at GSFC (0.13). This is attributed to calibration differences between the two instruments; hence comparisons should only be made between data taken on the same instrument. As-retrieved samples from both GSFC and GRC experienced an increase in solar absorptance, compared to pristine Al-FEP, with the exception of Bay 8 Region 3 (delaminated region), which was measured at GSFC without the inner layer. The GSFC absorptance of Bay 5 was slightly higher $(0.16)$ than pristine Al-FEP (0.13), while Bay 8 had a wide range of absorptance values, with the greatest absorptance for Bay 8 Region 13 (0.27). This is the region that was patched between SM2 and SM3B, and then exposed again to space. The data trends for absorptance changes are consistent for both GSFC and GRC, with the Bay 8 hazy-white region (Region 2) and the patched regions (Regions 11 and 13) having the greatest increases in solar absorptance.

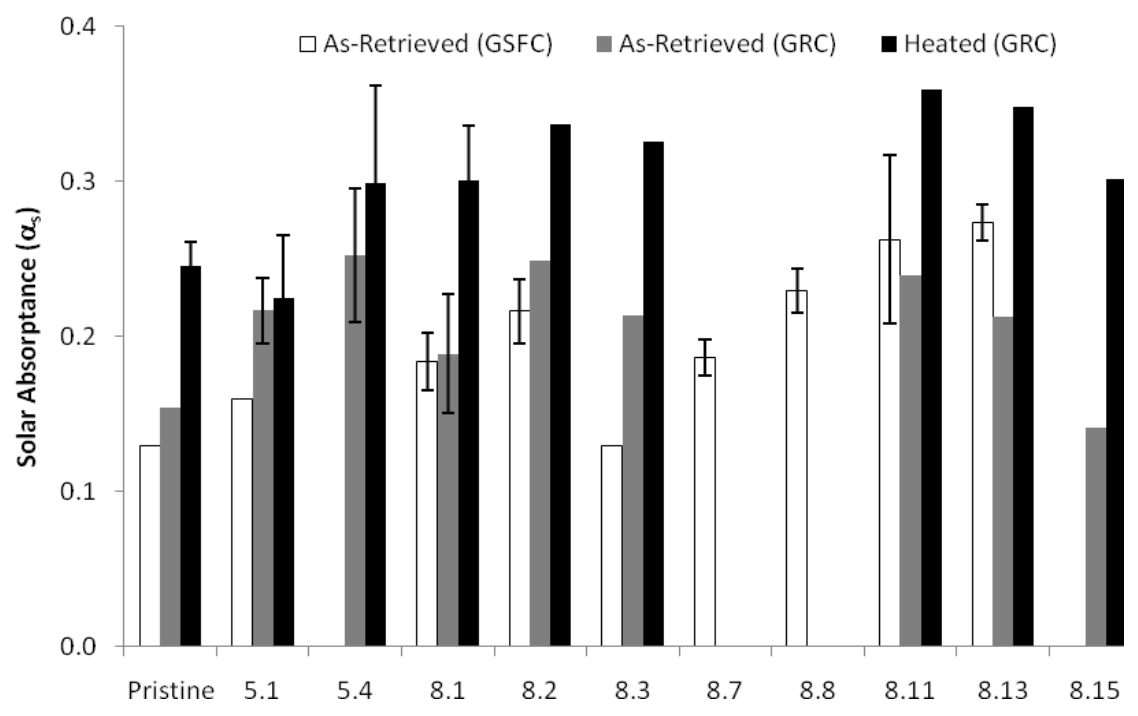

Figure 4.-As-retrieved and $120^{\circ} \mathrm{C}(96 \mathrm{hr})$ heated solar absortpance values. 


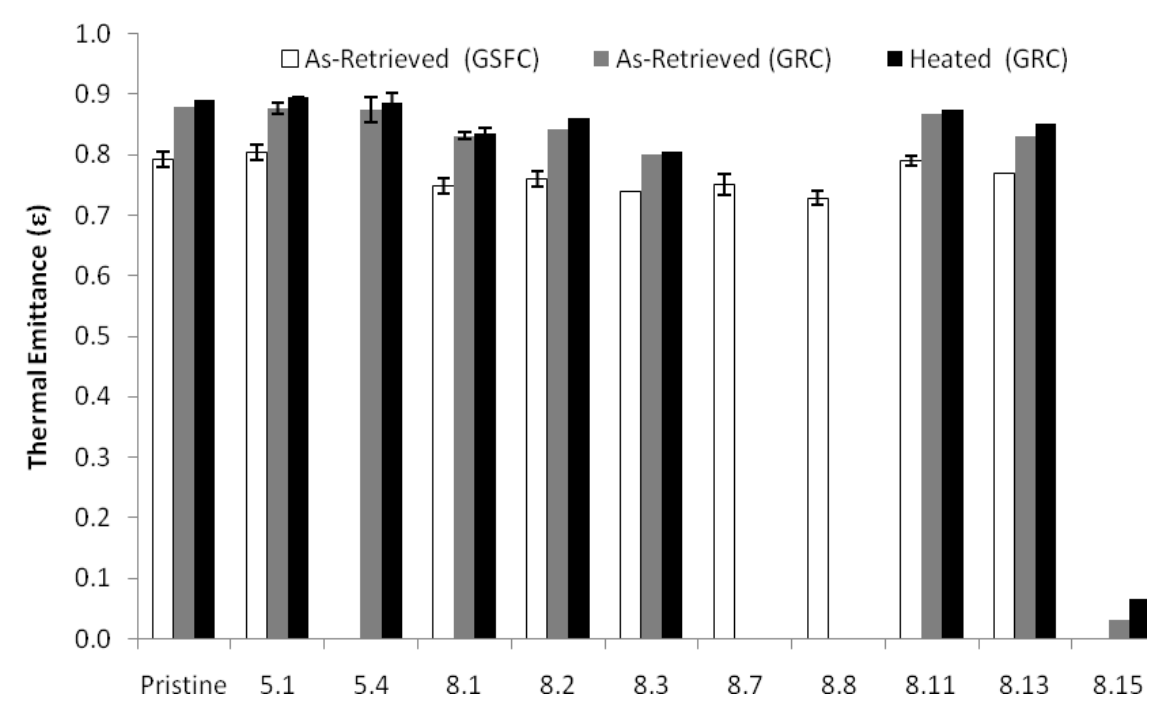

Figure 5.-As-retrieved and heated emittance values.

As stated previously, the GRC samples were measured with a piece of the inner layer embossed $\mathrm{Al} / \mathrm{Kapton} / \mathrm{Al}$ to best replicate the optical properties in space. As might be expected, the reflectance of the inner layer was found to have the biggest impact on the solar absorptance of the delaminated regions (5.4 and 8.3), increasing the absorptance significantly as compared to the GSFC data without the inner layer. Heating was found to increase the solar absorptance of the pristine Al-FEP by 0.09 . The Bay 8 Al-FEP experienced similar increases due to heating (0.09-0.11), with the regions that were covered by patches increasing even more (0.12-0.14). Although the Bay 5 thermal cycled to a lower maximum temperature on-orbit $\left(0^{\circ} \mathrm{C}\right)$ than Bay $8\left(40^{\circ} \mathrm{C}\right)$, the Bay 5 Al-FEP experienced very small increases in absorptance with heating as well. The reason for this is currently unknown.

The as-retrieved and heated thermal emittance values obtained at GSFC and GRC are plotted in Figure 5. The GSFC thermal emittance values were found to decrease for all samples except Bay 5 Region 1 and Bay 8 Region 11 (the region patched between SM2 and SM4). Emittance loss is typically associated with thickness loss of FEP, but for Bay 8 Regions 7 and 8, samples may have experienced additional emittance change due to excessive heating on-orbit or possibly from contamination. For example, if the emittance of silicone is lower than FEP then a thick enough layer of silicone contamination could decrease the emittance of the FEP. Similar to the GSFC emittance values, the GRC emittance was found to decrease for all samples except Bay 5 Region 1 (also Bay 5 Region 4) and Bay 8 Region 11, the region patched between SM2 and SM4. Heating had little impact on the emittance values of the retrieved HST MLI.

\section{X-Ray Photoelectron Spectroscopy (XPS)}

The XPS analyses for pristine Al-FEP and Regions 5.1, 8.1, 8.2, and 8.11 are provided in Table 2. As expected, the pristine Al-FEP is comprised of $\mathrm{C}$ (33.4 percent) and $\mathrm{F}$ ( 66.7 percent). The Bay 8 nominal regions $(1$ and 2$)$ were similar with an increase in $\mathrm{C}(\approx 39$ percent), a decrease in $\mathrm{F}(\approx 51$ percent) and the presence of $\mathrm{O}(\approx 6$ percent $), \mathrm{N}(\approx 2$ percent) and $\mathrm{Si}(0.4-1.2$ percent). Bay 8 Region 11 , which was patched from SM2-SM4 had a high concentration of C, possibly due to contamination from the Velcro patch. Surprisingly, Bay 5 was found to have a significant amount of Si contamination with the presence of 20 percent Si and 36 percent $\mathrm{O}$. The back of the solar arrays are coated with DC 93-500 silicone and because Bay 5 faces towards the $+\mathrm{V} 2$ solar array direction, the DC 93-500 is most likely the source of contamination. As only one area of Bay 5 was tested, additional tests could determine if silicone contamination is wide spread or localized on the blanket. This would be good to determine, particularly as silicone contamination could impact Ey values along with optical and thermal results. 
TABLE 2.-XPS RESULTS FOR ATOMIC PERCENT COMPOSITION

\begin{tabular}{|ccccccc|}
\hline $\begin{array}{c}\text { HST SM4 } \\
\text { material bay } \\
\text { region }\end{array}$ & \multicolumn{5}{c}{ Atomic \% } & \multirow{2}{*}{ F/C Ratio } \\
\cline { 2 - 6 } & $\mathrm{C}$ & $\mathrm{N}$ & $\mathrm{O}$ & $\mathrm{F}$ & $\mathrm{Si}$ & \\
\hline Pristine & 33.27 & 0.00 & 0.00 & 66.73 & 0.00 & 2.01 \\
\hline 5.1 & 19.44 & 1.12 & 36.36 & 22.56 & 20.52 & 1.16 \\
\hline 8.1 & 39.19 & 2.31 & 6.35 & 50.87 & 1.29 & 1.30 \\
8.2 & 39.50 & 2.12 & 5.43 & 52.55 & 0.41 & 1.33 \\
8.11 & 59.41 & 4.10 & 18.70 & 15.14 & 2.65 & 0.25 \\
\hline
\end{tabular}

In a study by de Groh et al. (Ref. 7), samples sectioned from Al-FEP circular thermal shields covering the bi-stem booms on the second set of HST solar arrays (retrieved after 8.25 years of space exposure) were examined with scanning electron microscopy for surface morphology and with energy dispersive spectroscopy (EDS) for surface chemistry. Pristine Al-FEP and solar-facing and anti-solar-facing thermal shield surfaces did not have any evidence of contamination, with only $\mathrm{C}$ and $\mathrm{F}$ peaks observed. However, a crazed surface texture was observed on one of the solar-grazing samples. The EDS data indicated the crazed texture is due to silicone contamination. Hence, the Bay 5 silicone contamination is consistent with contamination found on the solar-grazing surface of the retrieved solar array thermal shields, which is probably caused by contamination from the DC 93-500 silicone coating on the anti-solar side of the solar arrays.

\section{Atomic Oxygen Erosion Yield (Ey)}

Atomic oxygen Ey values determined through mass loss for the probable AO fluence are provided in Table 3. Because the AO fluence for Bay 8 Regions 7, 8, 11, and 13 were not computed, Ey values were not determined for these regions. The Ey value of the HST SM4 Bay 8 nominal shiny FEP $\left(E y=1.37 \times 10^{-23} \mathrm{~cm}^{3} /\right.$ atom) was found to be an order of magnitude greater than for the Bay 5 nominal shiny FEP $\left(\mathrm{Ey}=1.43 \times 10^{-24} \mathrm{~cm}^{3} /\right.$ atom $)$. This is attributed to the significantly higher dose of solar radiation, combined with the higher on-orbit temperature, for the solar facing blanket. These data provide evidence that solar exposure plays a significant role in the AO erosion of FEP.

Table 3 also provides the average Al-FEP thickness, Ey values calculated based on thickness loss and the ratio of thickness loss Ey to mass loss Ey. The two Ey methods gave consistent results, with thickness loss Ey $\sim 16$ percent higher than mass loss Ey. The reason for this difference is not known.

TABLE 3.-ATOMIC OXYGEN EROSION YIELD COMPARISON

\begin{tabular}{|cccccc|}
\hline $\begin{array}{c}\text { HST } \\
\text { material bay } \\
\text { region }\end{array}$ & Description & $\begin{array}{c}\text { Mass loss Ey } \\
\left(\mathrm{cm}^{3} / \text { atom }\right)\end{array}$ & $\begin{array}{c}\text { Average } \\
\text { thickness } \\
(\mathrm{cm})\end{array}$ & $\begin{array}{c}\text { Thickness loss } \\
\text { Ey } \\
\left(\mathrm{cm}^{3} / \text { atom }\right)\end{array}$ & $\begin{array}{c}\text { Ratio of } \\
\text { Ey(TL)/ } \\
\text { Ey(ML })\end{array}$ \\
\hline 8.1 & Shiny & $1.17 \mathrm{E}-23$ & 0.00722 & $1.37 \mathrm{E}-23$ & 1.17 \\
8.2 & White hazy & $8.22 \mathrm{E}-24$ & 0.00886 & $9.84 \mathrm{E}-24$ & 1.20 \\
8.3 & Al-delaminated & $1.12 \mathrm{E}-23$ & 0.00769 & $1.29 \mathrm{E}-23$ & 1.15 \\
\hline 5.1 & Shiny & $1.27 \mathrm{E}-24$ & 0.01241 & $1.43 \mathrm{E}-24$ & 1.12 \\
\hline $\mathrm{P}$ & Pristine & ---------- & 0.01308 & ---------- & ---- \\
\hline
\end{tabular}

${ }^{\mathrm{a}}$ Based on $130.1 \mu \mathrm{m}$ original thickness 
The Ey values of the HST SM4 FEP were found to be orders of magnitude greater than those determined from shuttle flight experiments such as the Evaluation of Oxygen Interaction with Materials III, reported from $5.0 \times 10^{-26} \mathrm{~cm}^{3} /$ atom (Ref. 8) to $1.8 \times 10^{-25} \mathrm{~cm}^{3} /$ atom (Ref. 9), the Long Duration Exposure Facility, determined to be $3.37 \times 10^{-25} \mathrm{~cm}^{3} /$ atom for ram facing surfaces (Ref. 10) and Materials International Space Station Experiments 2 (MISSE 2), determined to be $2.00 \times 10^{-25} \mathrm{~cm}^{3} /$ atom for ram facing surfaces (Ref. 11). Again, this is thought to be attributed to the effects caused by the significantly higher solar exposure of the HST materials.

\section{Summary and Conclusions}

Two MLI blankets retrieved from the HST during SM4 after 19.1 years in space have been analyzed for space-induced mechanical, optical and thermal properties. In addition, atomic oxygen Ey values were determined. The blankets experienced different solar exposures and thermal cycling temperature ranges, due to their positions on the telescope and each had regions with differing types of damage.

The mechanical properties of the blanket's Al-FEP outer-layers were extremely degraded. The Bay 8 Al-FEP, which had a significantly higher solar exposure and on-orbit thermal cycling temperature, was more embrittled than the solar-grazing Bay 5 insulation, and was found to fracture like thin brittle glass. Areas on Bay 8 which had been protected by a patch for a period of time on-orbit were slightly less embrittled than areas which had been exposed for all 19.1 years. However, even the least brittle samples still had only 3 percent of the elongation at failure of pristine materials. Heating pristine Al-FEP marginally decreased its strength, and had no effect on elongation. The Bay 8 MLI was too embrittled to conduct studies to assess the effect of heating, but heating Bay 5 Region 1 material reduced both the elongation and strength of the samples. The results of these tests support the proposed model for on-orbit degradation of Al-FEP, in which radiation causes chain scission of the polymers, and thermal heating to high temperature extremes causes the Al-FEP to become much more embrittled.

All space exposed samples experienced an increase in solar absorptance, as compared to pristine Al-FEP, with the exception of Bay 8 Region 3, which is the region where the Al has delaminated from the FEP. The greatest increase in absorptance occurred in the patched areas, likely due to contamination from the patches. The thermal emittance values were found to decrease for all samples except Bay 5 Region 1 and Bay 8 Region 11, the region patched between SM2 and SM4.

The Ey value of the HST SM4 Bay 8 nominal shiny FEP $\left(1.37 \times 10^{-23} \mathrm{~cm}^{3} /\right.$ atom $)$ was found to be an order of magnitude greater than for the Bay 5 nominal shiny FEP $\left(1.43 \times 10^{-24} \mathrm{~cm}^{3} /\right.$ atom $)$. This is attributed to the significantly higher dose of solar radiation, combined with the higher on-orbit temperature, for the solar facing blanket. The silicone contamination on Bay 5 may have decreased the Ey somewhat, but further studies are needed to assess this. The Ey values of the HST SM4 FEP were found to be orders of magnitude greater than those determined from prior flight missions, such as shuttle experiments $\left(0.5-1.8 \times 10^{-25} \mathrm{~cm}^{3} /\right.$ atom $), \operatorname{LDEF}\left(3.37 \times 10^{-25} \mathrm{~cm}^{3} /\right.$ atom $)$ and MISSE 2 experiments $\left(2.00 \times 10^{-25} \mathrm{~cm}^{3} /\right.$ atom $)$. These results support the belief that the effects of solar exposure play a significant role in the AO erosion of FEP.

\section{References}

1. Hansen, P.A., Townsend, J.A., Yoshikawa, Y., Castro, D.J., Triolo, J.J. and Peters, W.C., SAMPE International Symposium, 43, 570, (1998).

2. Townsend, J.A., Hansen, P.A., Dever, J.A., de Groh, K.K., Banks, B.A., Wang L. and He, C., High Perform. Polym. 11, 81-99 (1999).

3. Dever, J.A., de Groh, K.K., Banks, B.A., Townsend, J.A., Barth, J.L., Thomson, S., Gregory, T. and Savage, W., High Performance Polymers, 12, 125-139 (2000).

4. American Society for Testing and Materials ASTM D 638-95, "Standard Test Method for Tensile Properties of Plastics," 1995.

5. de Groh, K.K. and Martin, M.J. Spacecraft \& Rockets, 41 (3), 366-372 (2004). 
6. de Groh, K.K., Gaier, J.R., Hall, R.L., Espe, M.P., Cato, D.R., Sutter, J.K. and Scheiman, D.A., High Performance Polymers 12, 83-104 (2000).

7. de Groh, K.K., Finlay, K.A. and Snyder, A., High Performance Polymers, 20 (2008) 410-428.

8. Koontz, S.L., Leger, L.J., Visentine, J.T., Hunton, D.E., Cross, J.B. and Hakes, C.L., J. Spacecraft and Rockets, 32 (3), 483-495 (1995).

9. Rutledge, S.K., Banks, B.A. and Cales, M., NASA TM 106622; also AIAA-94-2628 (1994).

10. Banks, B.A., Chapter 4 in Modern Fluoropolymers: High Performance Polymers for Diverse Applications, edited by J. Scheirs, John Wiley \& Sons Ltd, 1997.

11. de Groh, K.K., Banks, B.A., McCarthy, C.E., Rucker, R.N., Roberts, L.M. and Berger, L.A., High Perform. Polymers, 20, 388-409 (2008). 


\begin{tabular}{|c|c|c|}
\hline \multicolumn{2}{|c|}{ REPORT DOCUMENTATION PAGE } & $\begin{array}{l}\text { Form Approved } \\
\text { OMB No. 0704-0188 }\end{array}$ \\
\hline \multicolumn{3}{|c|}{$\begin{array}{l}\text { The public reporting burden for this collection of information is estimated to average } 1 \text { hour per response, including the time for reviewing instructions, searching existing data sources, gathering and maintaining the } \\
\text { data needed, and completing and reviewing the collection of information. Send comments regarding this burden estimate or any other aspect of this collection of information, including suggestions for reducing this } \\
\text { burden, to Department of Defense, Washington Headquarters Services, Directorate for Information Operations and Reports (00704-0183), } 21215 \text { Jefferson Davis Highway, Suite } 21204 \text {, Arlington, VA } 22202-4302 \text {. } \\
\text { Respondents should be aware that notwithstanding any other provision of law, no person shall be subject to any penalty for failing to comply with a collection of information if it does not display a currently valid OMB } \\
\text { control number. } \\
\text { PLEASE DO NOT RETURN YOUR FORM TO THE ABOVE ADDRESS. }\end{array}$} \\
\hline $\begin{array}{l}\text { 1. REPORT DATE (DD-MM-YYYY) } \\
01-10-2012\end{array}$ & $\begin{array}{l}\text { 2. REPORT TYPE } \\
\text { Technical Memorandum }\end{array}$ & 3. DATES COVERED (From - To) \\
\hline \multirow{3}{*}{\multicolumn{2}{|c|}{$\begin{array}{l}\text { 4. TITLE AND SUBTITLE } \\
\text { Analyses of Hubble Space Telescope Aluminized-Teflon Insulation Retrieved After } 19 \text { Years } \\
\text { of Space Exposure }\end{array}$}} & 5a. CONTRACT NUMBER \\
\hline & & 5b. GRANT NUMBER \\
\hline & & 5c. PROGRAM ELEMENT NUMBER \\
\hline \multirow{3}{*}{\multicolumn{2}{|c|}{$\begin{array}{l}\text { 6. AUTHOR(S) } \\
\text { de Groh, Kim, K.; Waters, Deborah, L.; Mohammed, Jelila, S.; Perry, Bruce, A.; Banks, } \\
\text { Bruce, A. }\end{array}$}} & 5d. PROJECT NUMBER \\
\hline & & 5e. TASK NUMBER \\
\hline & & $\begin{array}{l}\text { 5f. WORK UNIT NUMBER } \\
\text { WBS } 315404.07 .20 .12\end{array}$ \\
\hline \multicolumn{2}{|c|}{$\begin{array}{l}\text { 7. PERFORMING ORGANIZATION NAME(S) AND ADDRESS(ES) } \\
\text { National Aeronautics and Space Administration } \\
\text { John H. Glenn Research Center at Lewis Field } \\
\text { Cleveland, Ohio 44135-3191 }\end{array}$} & $\begin{array}{l}\text { 8. PERFORMING ORGANIZATION } \\
\text { REPORT NUMBER } \\
\text { E-18321 }\end{array}$ \\
\hline \multirow{2}{*}{\multicolumn{2}{|c|}{$\begin{array}{l}\text { 9. SPONSORING/MONITORING AGENCY NAME(S) AND ADDRESS(ES) } \\
\text { National Aeronautics and Space Administration } \\
\text { Washington, DC 20546-0001 }\end{array}$}} & $\begin{array}{l}\text { 10. SPONSORING/MONITOR'S } \\
\text { ACRONYM(S) } \\
\text { NASA }\end{array}$ \\
\hline & & $\begin{array}{l}\text { 11. SPONSORING/MONITORING } \\
\text { REPORT NUMBER } \\
\text { NASA/TM-2012-217644 }\end{array}$ \\
\hline \multicolumn{3}{|c|}{$\begin{array}{l}\text { 12. DISTRIBUTION/AVAILABILITY STATEMENT } \\
\text { Unclassified-Unlimited } \\
\text { Subject Categories: } 27 \text { and } 18 \\
\text { Available electronically at http://www.sti.nasa.gov } \\
\text { This publication is available from the NASA Center for AeroSpace Information, 443-757-5802 }\end{array}$} \\
\hline
\end{tabular}

\section{SUPPLEMENTARY NOTES}

\section{ABSTRACT}

Since its launch in April 1990, the Hubble Space Telescope (HST) has made many important observations from its vantage point in low Earth orbit (LEO). However, as seen during five servicing missions, the outer layer of multilayer insulation (MLI) has become successively more embrittled and has cracked in many areas. In May 2009, during the 5th servicing mission (called SM4), two MLI blankets were replaced with new insulation pieces and the space-exposed MLI blankets were retrieved for degradation analyses by teams at NASA Glenn Research Center (GRC) and NASA Goddard Space Flight Center (GSFC). The MLI blankets were from Equipment Bay 8, which received direct sunlight, and Equipment Bay 5, which received grazing sunlight. Each blanket contained a range of unique regions based on environmental exposure and/or physical appearance. The retrieved MLI blanket's aluminized-Teflon (DuPont) fluorinated ethylene propylene (Al-FEP) outer layers have been analyzed for changes in optical, physical, and mechanical properties, along with space induced chemical and morphological changes. When compared to pristine material, the analyses have shown how the Al-FEP was severely affected by the space environment. This paper reviews tensile properties, solar absorptance, thermal emittance, x-ray photoelectron spectroscopy (XPS) data and atomic oxygen erosion values of the retrieved HST blankets after 19 years of space exposure.

\section{SUBJECT TERMS}

Hubble Space Telescope (HST); Thermal control insulation; Space environment; Extraterrestrial radiation; Environmental degradation; Polymer; Embrittlement; Absorptance; Emittance; Tensile properties

\begin{tabular}{|c|c|c|c|c|c|}
\hline \multicolumn{3}{|c|}{ 16. SECURITY CLASSIFICATION OF: } & \multirow{2}{*}{$\begin{array}{l}\text { 17. LIMITATION OF } \\
\text { ABSTRACT } \\
\text { UU }\end{array}$} & \multirow{2}{*}{$\begin{array}{l}\text { 18. NUMBER } \\
\text { OF } \\
\text { PAGES } \\
18\end{array}$} & \multirow{2}{*}{$\begin{array}{l}\text { 19a. NAME OF RESPONSIBLE PERSON } \\
\text { STI Help Desk (email:help@sti.nasa.gov) } \\
\text { 19b. TELEPHONE NUMBER (include area code) } \\
\text { 443-757-5802 }\end{array}$} \\
\hline $\begin{array}{l}\text { a. REPORT } \\
U\end{array}$ & $\begin{array}{l}\text { b. ABSTRACT } \\
U\end{array}$ & $\begin{array}{l}\text { c. THIS } \\
\text { PAGE } \\
\text { U }\end{array}$ & & & \\
\hline
\end{tabular}



